\title{
Molecular characterization and expression studies of Eucalyptus globulus stress-responsive gene DHN-10
}

\author{
G.Z. JAHANGIR ${ }^{1,2, *}$, S. NAZ² ${ }^{2}$, M.Z. SALEEM ${ }^{1}$, M.I. KHAN ${ }^{1}$, A. YOUNAS ${ }^{2}$, Z. QAMAR ${ }^{3}$, and Q. ALI ${ }^{4, *}$ (D) \\ ${ }^{1}$ Centre for Applied Molecular Biology, University of the Punjab, Lahore, 53700, Pakistan \\ ${ }^{2}$ Department of Biotechnology, Lahore College for Women University, Lahore, 54000, Pakistan \\ ${ }^{3}$ National Centre of Excellence in Molecular Biology, University of the Punjab, Lahore, 53700, Pakistan \\ ${ }^{4}$ Institute of Molecular Biology and Biotechnology, University of Lahore, Lahore, 54792, Pakistan
}

*Corresponding authors: E-mails: drsnaz31@hotmail.com, zahra_jahangir@yahoo.com, saim1692@gmail.com

\begin{abstract}
The Eucalyptus globulus is one of the important forest tree species which reveals enhanced tolerance to multiple abiotic stresses. The enhanced tolerance of E. globulus against low temperature is linked to the presence of enhanced accumulation of lysine-rich dehydrin proteins. The accumulation of dehydrin protein of $\mathrm{Mr} 10 \mathrm{kDa}$ in response to multiple abiotic stresses prevents cells from dehydration. It is encoded by a novel dehydrin-10 (DHN-10) gene. In the present study, we have used the $D H N-10$ gene of E. globulus of Pakistani origin, which was cloned in a bacterial expression vector pET30(a) and sequenced. We have found the $315 \mathrm{bp}$ long coding sequence of this gene which has been enrolled as Eucalyptus GZJ-2018 DHN-10 gene under GenBank accession number MG948256.1. The in silico studies have identified several differences of this gene from the earlier enrolled $D H N-10$ genes: the studied gene possessed higher amphipathic character because of the presence of five additional electrically charged amino acids (two positively charged histidine, one negatively charged glutamate, and two negatively charged aspartate residues) and one extra lysine residue. The studied $D H N-10$ gene has been successfully expressed in the BL21-DE3 expression strain of Escherichia coli and $10 \mathrm{kDa}$ protein has been detected on the nitrocellulose membrane. Our study is the first report of the sub-cloning of the DHN-10 gene and its expression outside the Eucalyptus cell.
\end{abstract}

Keywords: Escherichia coli expression strain, Eucalyptus dehydrin proteins, in silico analysis, sub-cloning.

\section{Introduction}

Drought, salinity, and frost result in dehydration of plant cells. The dehydration signals in plants trigger the synthesis of dehydration-induced cellular proteins (dehydrins) which were first observed in maize and barley in 1989 as reported in Yao et al. (2005) and Ali et al. (2014, 2016). Dehydrins belong to a multi-protein family called late embryogenesis abundant (LEA) proteins group-2 (Puhakainen et al. 2004, Yang et al. 2012). The dehydrins are located in the cytoplasm, nucleus, mitochondria, and chloroplast (Xu et al. 2005). Further, dehydrins have been found in the endoplasmic reticulum, plasma membrane, and tonoplasts (Close et al. 1993, Close 1996). The extensive accumulation of dehydrins has been observed in the plant embryos during later developmental stages, just like other LEA proteins (Hanin et al. 2011). The dehydrins accumulate extensively in all vegetative tissues when plants are subjected to environmental stresses that may cause the dehydration of cells like osmotic stress, drought, salinity, and heat (Hanin et al. 2011).

The dehydrins are hydrophilic and thermostable

Received 23 January 2019, last revision 5 August 2019, accepted 21 August 2019.

Abbreviations: IPTG - isopropyl $\beta$-D-1-thiogalactopyranoside; LEA - late embryogenesis; TA cloning - thymine-adenine cloning of PCR products.

Acknowledgements: Very passionate thanks are paid to Mr. Muhammad Munir Awan (CAMB) for his great help. We are also very thankful to the Plant Tissue Culture Lab (Department of Biotechnology, LCWU, Lahore) and CAMB DNA Core Facility (CAMB, University of the Punjab, Lahore; especially Mr. Muhammad Usman and Mr. Muhammad Akram) for their kind cooperation during execution of this work.

Conflict of interest: The authors declare that they have no conflict of interest. 
proteins with high content of electrically charged amino acids. Another characteristic of all dehydrins is that they possess a lysine-rich conserved sequence of 15 amino acids which is designated as the "K segment" (Saavedra et al. 2006, Graether and Boddington 2014). When the cellular hydration becomes low, the K-segments of dehydrin proteins adopt $\alpha$-helical structural conformation. The alterations in structural conformation of dehydrin proteins result in the altered function of these proteins. The phenomenon of structural alterations is known as "moonlighting" and it is the main characteristic of intrinsically disordered/unstructured proteins (IDPs/ IUPs). When IDPs/IUPs perceive signals of changes of hydration (availability/deficiency) in a microenvironment, they undergo conformational changes leading to functional changes. The $\alpha$-helices of dehydrin proteins (designated as amphipathic $\alpha$-helices) have been found important for developing interactions with dehydrated surfaces of biomembranes and other cellular proteins. When the dehydrin molecule is in $\alpha$-helical conformation then its numerous K-segments can form bundles. This feature enhances the interaction of dehydrin with biomembranes and other cellular proteins which enhances the stress tolerance of cells (Hanin et al. 2011). Dehydrins can also be exploited for the management of excessive metal ions and reactive oxygen species (ROS) in the cells under stressful conditions. Because some of the dehydrin proteins have been discovered to contain a relatively higher content of histidine/arginine or other reactive amino acids on the surface, they have also been reported for possessing properties to bind with metal ions and scavenge the ROS or reactive oxygen species in the cells under stress conditions (Hanin et al. 2011).

Eucalyptus is an important forest species with enhanced tolerance against abiotic stresses. The dehydrin-10 protein of Eucalyptus of $10 \mathrm{kDa}$ (DHN-10), has been reported responsible along with other two dehydrin proteins (dehydrin-1 and dehydrin-2) for conferring abiotic stress tolerance to Eucalyptus globulus (Fernandez et al. 2012). Dehydrin-10 has still not been well studied for its manipulation purposes and similar expression outside of the Eucalyptus cells. The natural expression of dehydrin proteins is abscisic acid-dependent as well as independent of its normal functioning in the cells. The aim of the presented study was a detailed molecular characterization of dehydrin protein of Eucalyptus globulus and DHN-10 expression in Escherichia coli strain BL21-DE3.

\section{Materials and methods}

Plants and isolation of $\mathbf{D H N}-10$ gene: For nucleic acid extraction, the plant tissues were obtained from Eucalyptus globulus trees of saline and water logged areas of Lahore Division (Punjab). The RNA and DNA were isolated from different tissues like fleshy green twig tissues, woody green twig tissue, hard bark, older hard leaves, young soft leaves and young floral buds of apparently older trees as described by Jahangir et al. (2018). The full-length $D H N$ 10 , as well as its coding regions (mRNA through cDNA), were amplifed using gene specific forward and reverse primers; and cloned via thymine-adenine (TA) cloning of PCR products (TA cloned; Jahangir et al. 2018).

Sequencing and in silico analyses: The TA cloned fulllength and coding region of the Eucalyptus globulus gene were sequenced using commercial sequencing facility of Centre for Applied Molecular Biology (CAMB, Lahore, Pakistan). The detected gene sequences were manually analyzed using Chromas v. 1.45 software (http://technelysium.com.au/wp/chromas/). Verification of analyzed sequences was done at $N C B I$ through $B L A S T n$ (http://www.ncbi.nlm.nih.gov/BLAST/) by comparing with reported sequences of Eucalyptus DHN-10. Using ExPASY translating tool (www.expasy.org), the FASTA format of DNA files was translated into amino acid sequences. Further bioinformatic analysis was done using different tools including multiple sequence alignment assay (MSA), UniProt, and ProtParam (MSA performed on Uniprot.org and physiochemical analysis was done on EXPASY ProtParam tool).

Sub-cloning of $\boldsymbol{D H} \mathbf{N}-10$ gene in pET30(a): The $D H N-10$ has not been reported earlier to be manipulated for gene expression studies. The coding region of $D H N-10$ was cloned into $E$. coli expression vector, pET30(a), to identify the possibility of expression of $D H N-10$ outside the Eucalyptus cells. The intron-less, central coding region was amplified from TA cloned full-length gene with primers having restriction sites of EcoR1 and HindIII enzymes. The primers were designed using Primer 3 software, named as $\mathrm{C}-1$ primers with the following sequences: forward 5'-GAATTCATGGCGGGAATCATCCACAAGATC-3' and reverse 5'-AAGCTTACAGCTATCAGTCGGGCA AT-3'. The optimized PCR formulation contained $100 \mathrm{ng}$ plasmid template (TA cloned full length Eucalyptus DHN10 gene was used as template during its amplification which had central single exon with two introns on both sides), $0.001 \mathrm{nmol}$ of both forward and reverse primers, $1 \times$ PCR master mix (Thermo Fisher Scientific Baltics, Vilnius, Lithuania), and nuclease-free water to a final volume of $30 \mathrm{~mm}^{3}$. The optimized cycling conditions were initial denaturation at $95^{\circ} \mathrm{C}$ for $5 \mathrm{~min}$, then $95^{\circ} \mathrm{C}$ for $45 \mathrm{~s}$, $54{ }^{\circ} \mathrm{C}$ for $45 \mathrm{~s}, 72{ }^{\circ} \mathrm{C}$ for $1 \mathrm{~min}$, and final extension at $72{ }^{\circ} \mathrm{C}$ for $7 \mathrm{~min}$ in Kyratec thermal cycler (Queensland, Australia) super cycler $(S C 300 G)$ with 30 repeats. The amplified coding sequence of $D H N-10$ with added restriction sites for EcoR1 and HindIII restriction enzymes on upstream and downstream edges, respectively, was TA cloned into $\mathrm{pTZ} 57 \mathrm{R} / \mathrm{T}$ vector following the instructions of the manufacturer (Thermo Scientific InsTA PCR cloning kit). The TA cloned construct (named C-1 construct) was transformed into competent $E$. coli strain Top $10 \mathrm{~F}$ following the previously optimized protocols (Jahangir et al. 2018). Successful ligation of the amplicon was assessed by restriction digestion and PCR amplification of purified plasmid from true transformants. The tested pTZ57R/T plasmid having C-1 construct and empty pET30(a) were double digested with EcoR1 and HindIII enzyme pair. The released insert from construct and linearized pET30(a) 
having cut ends were purified with Quick Gel Elusion kit (Invitrogen, Carlsbad, USA). The purified gene insert of C-1 with cut ends was ligated into the purified, linear, empty pET30(a) vector using Thermo Scientific ligase enzyme and ligation buffer (InsTAclone PCR cloning kit). The $30 \mathrm{~mm}^{3}$ ligation reaction mixture contained $10 \mathrm{~mm}^{3}$ of purified digestion product (purified insert) and $5 \mathrm{~mm}^{3}$ of digested empty pET30(a) vector, $1 \times$ final concentration of ligation buffer, $8 \mathrm{~mm}^{3}$ of nucleases free water, and $1 \mathrm{~mm}^{3}$ of T4 DNA ligase. It was incubated at $8-10^{\circ} \mathrm{C}$ overnight. Then, $10 \mathrm{~mm}^{3}$ of the ligation product of plasmid pET30(a) and $\mathrm{C}-1$ (named $\mathrm{C}-1 / \mathrm{pET}$ construct) was transformed into competent $E$. coli Top $10 \mathrm{~F}$ following the methodology of Jahangir et al. (2018). In these experiments, kanamycin $\left(50 \mu \mathrm{g} \mathrm{cm}^{-3}\right.$ ) was used for the selection of pET30(a) along with $12.5 \mu \mathrm{g} \mathrm{cm}^{-3}$ of tetracyclin for selection of Top10F'. The purified plasmid from true transformants was tested for exact integration through PCR and restriction digestion. The optimized reaction mixture $\left(50 \mathrm{~mm}^{3}\right)$ for double digestion of $\mathrm{C}-1 / \mathrm{pET}$ construct contained $8 \mathrm{~mm}^{3}$ of purified construct plasmid, $1 \mathrm{~mm}^{3}$ of EcoRI (15 $\left.\mathrm{U} \mathrm{mm}^{-3}\right), 2 \mathrm{~mm}^{3}$ of HindIII $\left(15 \mathrm{U} \mathrm{mm}^{-3}\right)$, $5 \mathrm{~mm}^{3}$ of buffer $\mathrm{M}(10 \times)$, and $35 \mathrm{~mm}^{3}$ of nucleases free water $\left(3 \mathrm{~h}\right.$ incubation at $37^{\circ} \mathrm{C}$ was provided for complete digestion). The tested plasmid was transformed into competent cells of E. coli strain BL21-DE3 following the E.coli transformation method (Jahangir et al. 2018). The obtained transformants were again tested through PCR amplification with gene-specific primers and double restriction digestion with EcoR1 and HindIII enzymes.

Expression of Eucalyptus DHN-10 protein in BL21DE3: Single colony raised from confirmed C-1/pET/ BL21 clone on selection media was incubated overnight at $30{ }^{\circ} \mathrm{C}$ in $3 \mathrm{~cm}^{3} \mathrm{LB}$ broth (Lennox \# LAB-173) having kanamycin $\left(50 \mu \mathrm{g} \mathrm{cm}^{-3}\right)$. The enriched culture was diluted in the same medium $\left(10 \mathrm{~cm}^{3}\right)$ and multiplied at similar conditions until an absorbance $\mathrm{A}_{600}$ was 0.7 which was attained in $4 \mathrm{~h}$. The $1 \mathrm{~cm}^{3}$ of enriched culture was saved at $-20^{\circ} \mathrm{C}$ to use as an un-induced sample. Isopropyl $\beta$-D-1thiogalactopyranoside (IPTG) was added to the rest of the culture to attain the concentration of $1 \mathrm{mM}$ and incubated again at the same conditions for $3 \mathrm{~h}$. After incubation, the culture was cooled on ice for $20 \mathrm{~min}$ and dispensed into $1 \mathrm{~cm}^{3}$ aliquots. The cultured cells were harvested by centrifugation at $5000 \mathrm{~g}$ and $4{ }^{\circ} \mathrm{C}$ for $20 \mathrm{~min}$. The pellets of induced and not induced C-1/pET/BL21 cells were resuspended in $100 \mathrm{~mm}^{3}$ of $100 \mathrm{mM}$ phosphate buffer saline (PBS). The $40 \mathrm{~mm}^{3}$ from each suspension was mixed separately with $7 \mathrm{~mm}^{3}$ of $6 \times$ protein loading buffer $\left(10 \mathrm{~cm}^{3}\right.$ of $6 \times$ protein loading buffer was prepared from $1.2 \mathrm{~g}$ sodium dodecyl sulphate (SDS), $1.2 \mathrm{~cm}^{3}$ of $0.5 \mathrm{M}$ Tris$\mathrm{HCl}(\mathrm{pH} 6.0), 0.01 \%(\mathrm{~m} / \mathrm{v})$ Bromophenol Blue, $4.7 \mathrm{~cm}^{3}$ of glycerol, $2.1 \mathrm{~cm}^{3}$ of water) and boiled in a water bath for $10 \mathrm{~min}$ to denature the proteins. The tubes were then immediately shifted to the ice for $10 \mathrm{~min}$. Both heating and cooling were repeated once again but each for $5 \mathrm{~min}$. Then the tubes were centrifuged at $14000 \mathrm{~g}$ and $4{ }^{\circ} \mathrm{C}$ for $10 \mathrm{~min}$ and $20 \mathrm{~mm}^{3}$ of protein samples were loaded on $30 \%(\mathrm{~m} / \mathrm{v})$ polyacrylamide gel prepared according to standard SDS-PAGE protocol (Laemmli 1970) in Hoefer Mini. After resolving the gel at $80 \mathrm{~V}$ for $45 \mathrm{~min}$ followed by $120 \mathrm{~V}$ for $2.5 \mathrm{~h}$, it was stained with Coomassie stain for $45 \mathrm{~min}$. After proper staining, the gel was several times destained for clearing of a blue background. Then the gel was analysed for the presence of approximately $10 \mathrm{kDa}$ protein of Eucalyptus DHN-10 in a protein mixture of induced and non-induced BL21 cells.

Protein Dot Blot analysis: The pellets of $1 \mathrm{~cm}^{3}$ from induced and non-induced C-1/pET/BL21 cultures were directly resuspended in $100 \mathrm{~mm}^{3}$ of protein sample buffer for dot blot analysis $\left(50 \mathrm{~cm}^{3}\right.$ of protein sample buffer was prepared from $24 \mathrm{~g}$ of urea, $2.5 \mathrm{~g}$ of SDS, $2 \mathrm{~cm}^{3}$ of $1 \mathrm{M}$ Tris- $\mathrm{HCl}$ (pH 6.8), $10 \mathrm{~mm}^{3}$ of $0.5 \mathrm{M}$ EDTA, and $0.5 \mathrm{~cm}^{3}$ 2-mercaptoethanol) in $1.5 \mathrm{~cm}^{3}$ centrifuge tubes and incubated in boiling water bath for $10 \mathrm{~min}$. Then the tubes were placed at $-20^{\circ} \mathrm{C}$ for $5 \mathrm{~min}$. The tubes were again shifted to boiling water bath for another $10 \mathrm{~min}$. Finally, the tubes were centrifuged at $14000 \mathrm{~g}$ and $4{ }^{\circ} \mathrm{C}$ for $10 \mathrm{~min}$, and 7 $\mathrm{mm}^{3}$ of the supernatant containing crude protein extract was blotted on the Hybond-C membrane. The protein samples from induced and non-induced cells were blotted on the membrane separately and in triplicates. The membrane was air-dried in a laminar airflow cabinet for $20 \mathrm{~min}$. Then membrane was blocked in $5 \%$ blocking buffer $(100 \mathrm{mM}$

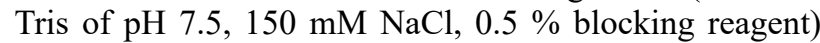
for $1 \mathrm{~h}$. The membrane was soaked in Anti-His antibody (Roche) diluted to $1 \mathrm{~mm}^{3} \mathrm{~cm}^{-3}$ in the above-blocking buffer for $35 \mathrm{~min}$ at shaking (primary antibody: His-probe $\mathrm{H}-15$, rabbit polyclonal $\mathrm{Ig} / \mathrm{G} 200 \mu \mathrm{g} \mathrm{cm}^{-3}$ ). Then primary antibody was removed for secondary antibody diluted in the same solution (Anti-Rabbit $\mathrm{Ig} / \mathrm{G} 200 \mu \mathrm{g} \mathrm{cm}^{-3}$ ) and the membrane was shaken for $30 \mathrm{~min}$. Finally, the membrane was dipped in substrate solution of NBT-BCIP (Roche; 1 tablet per $10 \mathrm{~cm}^{3}$ autoclaved double distilled water) and put for colour development in dark for 5 - $10 \mathrm{~min}$.

\section{Results}

The TA cloned full-length $D H N-10$ gene of Eucalyptus globulus, as well as its coding region, were sequenced from $C A M B$ commercial sequencing facility. The $315 \mathrm{bp}$ long coding sequence was submitted in NCBI data bank as GZJ-2018 dehydrin-10 under accession number GZJ-2018 dehydrin-10 (GenBank: MG948256.1) after confirmation by comparing with reported mRNA sequence of $D H N-10$ gene of Eucalyptus globulus (GenBank: JN052210.1). It produced significant alignment with $100 \%$ query cover and $93 \%$ homology. The submitted sequence was translated on the Expasy translate tool and was analyzed on ProtParam (Fig. 1 Suppl.). The coding sequence of Eucalyptus sp. GZJ-2018 dehydrin-10 gene was 315 bp long whereas the already published coding sequence of the $D H N-10$ gene (JN052210.1) possesses 297 bp. 114 amino acids are present in GZJ-2018 dehydrin-10 protein with a total molecular mass of $12889.92 \mathrm{Da}$ and theoretical pI of 6.13. This protein contains 29 negatively charged residues (Asp and Glu) and 22 positively charged residues (Arg and Lys). 


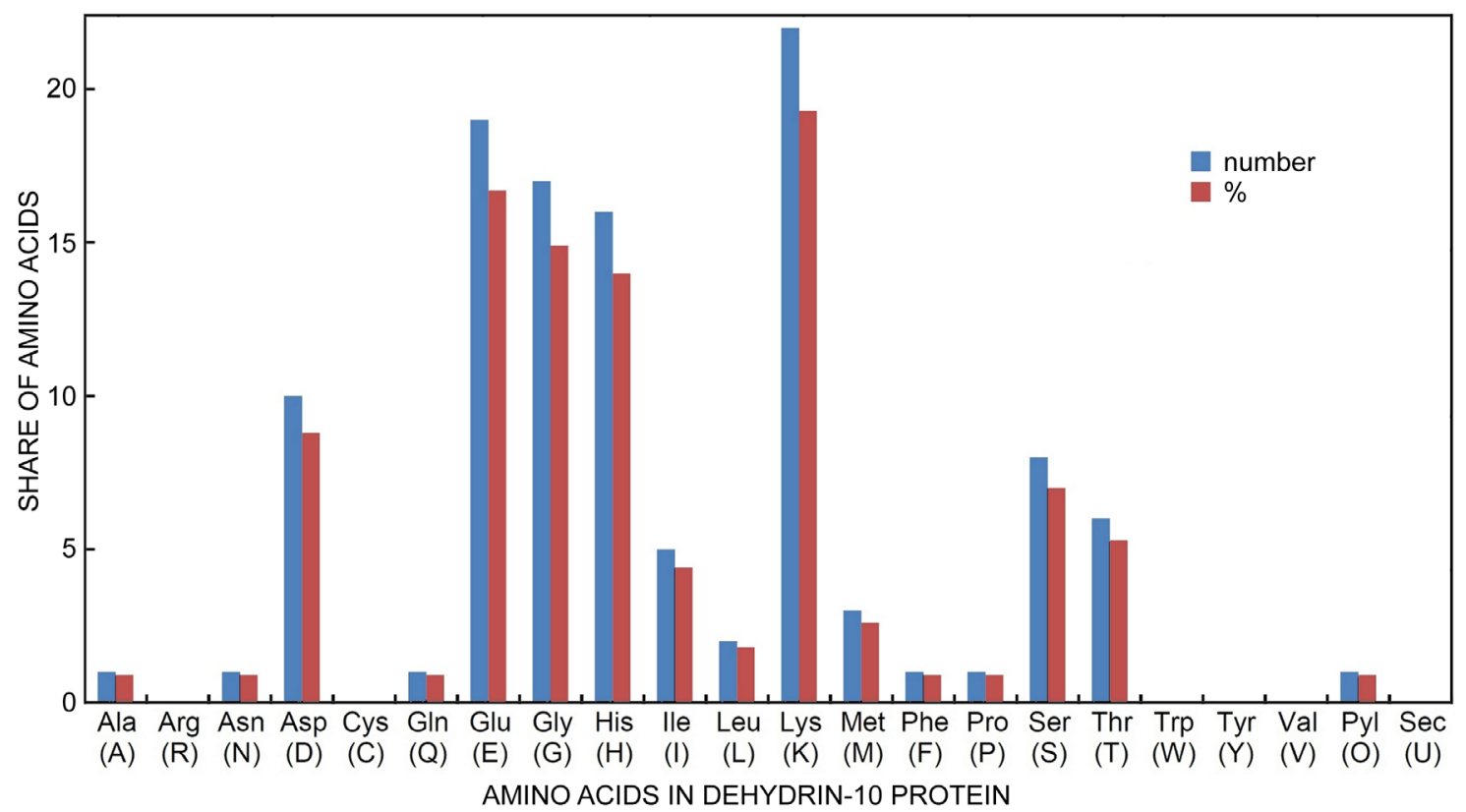

Fig. 1. Percentage share of different amino acids in Eucalyptus sp. DHN-10 protein.

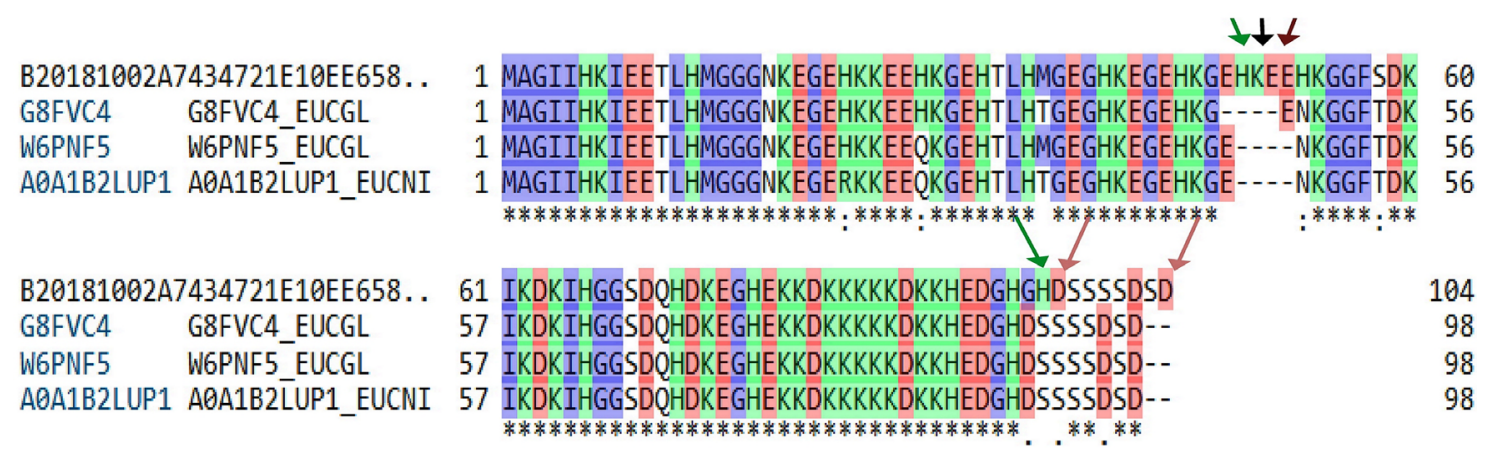

Fig. 2. A comparison of hydrophobic, positively, and negatively charged amino acids in Eucalyptus sp. DHN-10 protein with reported DHN-10 proteins. The first sequence belongs to the currently studied Eucalyptus sp. GZJ-2018 dehydrin-10 protein (MG948256.1) and it is compared with three other most closely related published sequences of same protein of E. globulus and E. nitens, present in NCBI data bank. G8FVC4: DHN-10 protein of E.globulus (AER27689.1); W6PNF5: DHN-10 protein of E.globulus DHN-10 (HG915712.1); A0A1B2LUP1 is the DHN-10 protein of E. nitens (KU674824.1)
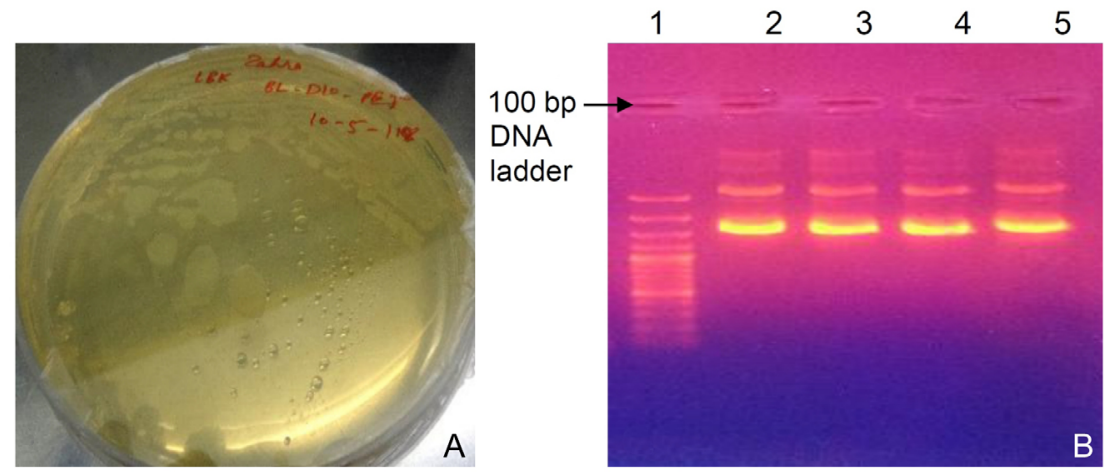

Fig. 3. Transformation of C-1/pET30(a) plasmid in E. coli BL21-DE3 strain. A - Single colonies of BL21-DE3 grown on kanamycin selection medium. $B$ - C-1/pET30(a) plasmid purified from broth cultures: 1 - 100 bp DNA ladder; 2 to 5 - C-1/pET30(a) plasmids purified from BL21.

The submitted GZJ-2018 dehydrin-10 sequence possesses extra integration of two positively charged histidine, one negatively charged glutamate residue, two negatively charged aspartate residues, and one extra lysine residue 


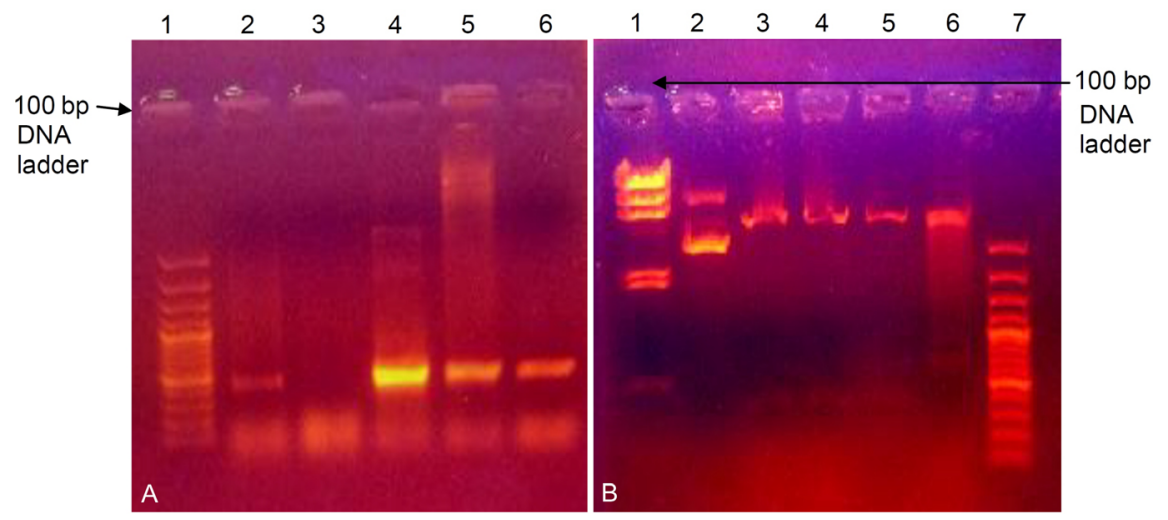

Fig. 4. Confirmation of C-1/pET/BL21 construct in BL21-DE3 by PCR $(A)$ and restriction digestion $(B) . A-1-100$ bp DNA ladder, 2 - PCR positive control (C-1/pTZ plasmid template and C-1 primers), 3 - PCR negative control (water template and C-1 primers); 4 to 6- PCR with C-1/pET30(a) plasmid template from BL21 and C-1 primers. $B$ - 1 - Lambda HindIII DNA marker, 2 - C-1/pET30(a) undigested; 3 to 5 - the same C-1/pET30(a) plasmids digested with EcoRI and HindIII enzymes, 6 - empty pET30(a) plasmids digested with EcoRI and HindIII enzymes, 7 - 100 bp DNA ladder.

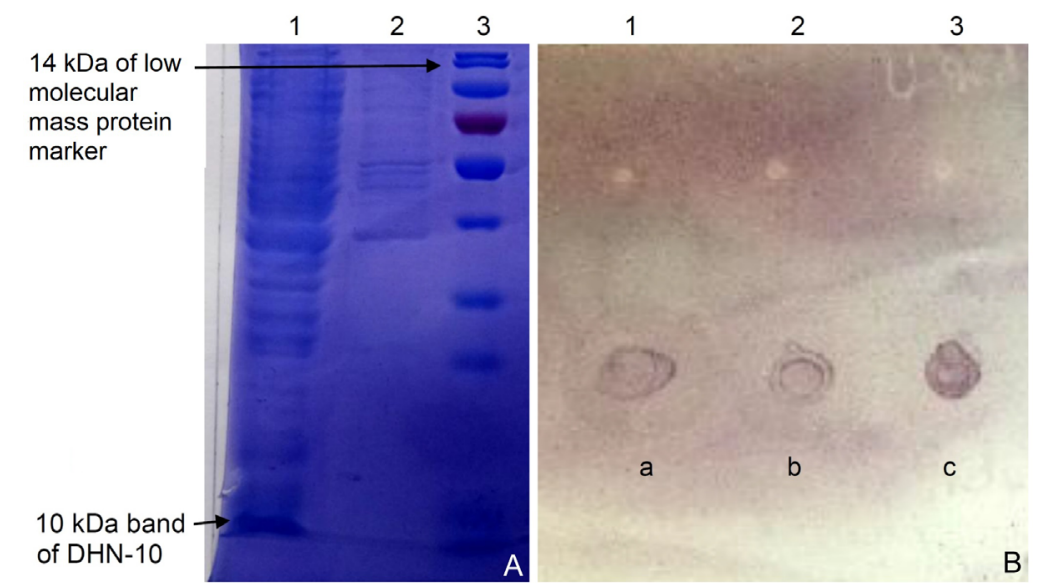

Fig. 5. Expression analysis of Eucalyptus DHN-10 protein in E.coli BL21-DE3. A - SDS-PAGE analysis: 1 - induced C-1/pET/BL21 culture, 2 - the same C-1/pET/BL21 culture but non-induced, 3 - low molecular mass protein marker (14 kDa ). B - Protein dot blot analysis: 1 to 3 - C-1/pET/BL21 in non-induced culture in triplicate; a-c - C-1/pET/BL21 in induced culture in triplicate.

(Figs. 1 and 2). Furthermore, no Trp, Tyr, or Cys amino acids were present in GenBank MG948256.1 (Fig. 1). Hence, the quantification of this protein was not possible through UV spectrophotometry. The Eucalyptus sp. GZJ2018 dehydrin-10 protein showed significant alignment with dehydrin-10 protein of two Eucalyptus species, the $E$. nitens, and E. globulus; but earlier possesses $\mathrm{H}, \mathrm{K}, \mathrm{E}$, and $\mathrm{S}$ amino acids that are extra inserted than both later ones, the E. nitens, and E. globulus (Fig. 2 Suppl.).

The coding regions of Eucalyptus sp. GZJ-2018 dehydrin-10 gene was amplified from full-length TA cloned $D H N-10$ gene with C-1 primer set and $D H N-10$ gene with added restriction sites of EcoRI and HindIII on both ends was obtained. The same template was also amplified using a gene-specific primer set for full length (525 bp) amplification as PCR positive control. The gene specific primers that were designed using published sequence of $D H N-10$ gene (JN052210.1) amplified the coding sequence of DHN-10 gene from Eucalyptus globulus of Lahore Division with significant differences. The latter (MG948256.1) had 18 base pairs more than the former
(JN052210.1). The purified PCR product of the coding region having restriction sites was cloned into $\mathrm{pTZ}$ T7R/T vector. The resulting $\mathrm{C}-1 / \mathrm{pTZ}$ construct was transformed into E. coli Top10F' strain. Product of double digestion (with EcoRI and HindIII enzymes) of tested and confirmed C-1/pTZ plasmid was ligated in empty pET30(a) vector (5 $422 \mathrm{bp}$ ), digested with the same enzyme pair, and transformed in Top10F' strain. The recombinant purified plasmid of survived transformants on kanamycin selection medium produced PCR bands of $>315 \mathrm{bp}$ (315 bp coding region plus restriction sites of EcoR1 and HindIII restriction enzymes with $\mathrm{C}-1$ primers). A 315 bp insert released on double digestion of the plasmid with EcoR1 and HindIII enzyme pair. The digested pET30(a) vector remained slightly below the upper third band (of $6000 \mathrm{bp}$ ) of the $1 \mathrm{~kb}$ DNA ladder. The confirmed plasmid construct (C-1/pET30(a) was transformed in competent cells of the BL21-DE3 strain of $E$. coli (Fig. $3 A$ ). The transformation event was also verified through purification of the $\mathrm{C}-1 /$ pET30(a) construct (Fig. 3B), PCR (Fig. 4A), and double restriction digestion (Fig. $4 B$ ). The protein extract from 
induced and non-induced cell pellet of C-1/pET/BL21 clone was observed on SDS-PAGE. A prominent $10 \mathrm{kDa}$ band was visible in induced cell protein whereas no band was observed in a non-induced pellet of the same culture (Fig. 5A). The crude protein extract from the same $\mathrm{C}-1 /$ $\mathrm{pET} / \mathrm{BL} 21$ clone of induced and non-induced culture was also blotted on nitrocellulose membrane Hybond $C$ for protein dot blot analysis. Secondary antibody-NBT/BCIP substrate color reaction confirmed the production of DHN10 protein in induced BL21 cells from transformed C-1/ pET30(a) plasmid (Fig. 5B). No protein production was observed in the same culture without the induction of a strong T7 promoter. These observations indicated that the DHN-10 gene of Eucalyptus can be successfully expressed outside the parent cell, in an entirely different expression system, if an appropriate promoter is provided.

\section{Discussion}

The presence of one extra lysine residue in studied DHN-10 (MG948256.1) can be expected for enhanced amphipathic quality which is related to the binding of dehydrin proteins with macromolecules. As dehydrin proteins are molecules with characteristic lysine-rich K-segments, the presence of extra $\mathrm{K}$ amino acid residue will aid to all of the specific functions that are linked to or influenced with K-segment. The K-segment is involved in the formation of an amphipathic helix and plays an important role in dehydrinmacromolecules interaction (Close 1996, Close et al. 1993). On the perception of dehydration signals from the microenvironment of cell, K-segments adopt characteristic $\alpha$-helical conformation (Hanin et al. 2011). It is the response mechanism of the plant cells to abiotic stresses. Koag et al. (2003) have stated that conformational changes in the $\mathrm{K}$ segment of dehydrin proteins enhance their role in stabilizing the membranes of a cell during dehydration conditions. The presence of five extra charged amino acid residues like two positively charged histidine, one negatively charged glutamate, and two negatively charged aspartate residues (Fig. 2) in studied DHN-10 protein has enhanced its importance because the dehydrins with higher content of reactive amino acids on the surface possess free metal ion binding and so ROS scavenging properties (Hanin et al. 2011). Free metal ions are also involved, as catalyzers, in the synthesis of reactive oxygen species. Therefore, the removal of free metal ions from the medium reduces the synthesis of various ROS (Hara et al. 2001, 2005, Heyen et al. 2002, Hanin et al. 2011). Dehydrins are highly hydrophilic proteins that help other biomolecules to maintain high configurational flexibility and defy the unspecific aggregation and collapse (Mouillon et al. 2006, Koag et al. 2009).

The Eucalyptus DHN-10 gene was not reported earlier to be cloned or expressed in any expression system outside the Eucalyptus species. It is the first report showing the possibility to be sub-cloned in a bacterial expression vector, pET30(a). The induced expression of $D H N-10$ is also first time reported in E.coli strain BL21-DE3. Cloned $D H N-10$ gene was found to be successfully translated into a stable protein that was detected in protein dot blot analysis. Although no report could be found upon genetic cloning and expression of Eucalyptus dehydrin genes in the expression vector, however, a significant mass of work has been conducted on sequence study of dehydrin genes. Some other researchers have cloned diverse dehydrin genes from a variety of plant species. For instance, Zeng et al. (2018) have cloned the RNA sequence of the $L E A$ gene family from Gastrodia elata into $E$. coli to evaluate their function under low-temperature stress. A novel SK3 type dehydrin of the Stipa purpurea plant has been studied and cloned by Yang et al. (2014). Yao et al. (2005) have also reported novel dehydrins in a specific subclass of the LEA protein family from Brassica juncea and Brassica napus. Full-length cDNA of dehydrin-like protein of Pistacia vera has been reported to be cloned by Yakubov et al (2005).

\section{Conclusions}

We successfully cloned and expressed the novel dehydrin-10 gene from the Eucalyptus globulus of Pakistani origin. The in silico analyses of the $D H N-10$ gene revealed presence of five additional electrically charged amino acids (two positively charged histidine, one negatively charged glutamate, and two negatively charged aspartate residues) and one lysine. The $D H N-10$ was successfully cloned in a bacterial expression vector (pET30(a)) and its expression was detected in E. coli. The expressed $D H N-10$ possesses enhanced characteristics of abiotic stress tolerance because of the presence of one additional lysine residue which is directly involved in the amphipathic characteristic of dehydrins. Furthermore, DHN-10 can also be expected to be involved in antioxidation activity because of the presence of five additional charged residues that indicates the possible involvement of DHN-10 (MG948256.1) as an anti-oxidant molecule in the cell which is also a characteristic of a stress response. The present study will be helpful in future practices of cloning and expression of novel dehydrins and dehydrin-like genes.

\section{References}

Ali, Q., Ahsan, M., Kanwal, N., Ali, F., Ali, A., Ahmed, W., Ishfaq, M., Saleem, M.: Screening for drought tolerance: comparison of maize hybrids under water deficit condition. Adv. Life Sci. 3: 51-58, 2016.

Ali, Q., Ali, A., Ahsan, M., Ali, S., Khan, N.H., Muhammad, S., Abbas, H.G., Nasir, I.A., Husnain, T.: Line $\times$ Tester analysis for morpho-physiological traits of Zea mays L. seedlings. Adv. Life Sci. 1: 242-253, 2014

Close, T.J. Dehydrins: emergence of a biochemical role of a family of plant dehydration proteins. - Physiol. Plant. 97: 795803, 1996.

Close, T.J., Lammers, P.J. An osmotic stress protein of cyanobacteria is immunologically related to plant dehydrins. Plant Physiol. 101: 773-779, 1993.

Fernandez, M., Aguila, V.S., Arora, R., Chen, K.: Isolation and characterization of three cold acclimation-responsive 
dehydrin genes from Eucalyptus globulus. - Tree Genet. Genomes 8: 149-162, 2012.

Graether, S.P., Boddington, K.F.: Disorder and function: a review of the dehydrin protein family. - Front. Plant Sci. 5: 576, 2014.

Hanin, M., Brini, F., Ebel, C., Toda, Y., Takeda, S., Masmoudi, K.: Plant dehydrins and stress tolerance: versatile proteins for complex mechanisms. - Plant Signal Behav. 6: 1503-1509, 2011.

Hara, M., Fujinaga, M., Kuboi, T:. Metal binding by citrus dehydrin with histidine-rich domains. - J. exp. Bot. 56: 2695$2703,2005$.

Hara, M., Terashima, S., Kuboi, T.: Characterization and cryoprotective activity of cold-responsive dehydrin from Citrus unshiu. - J. Plant Physiol. 158: 1333-1339, 2001.

Heyen, B.J., Alsheikh, M.K., Smith, E.A., Torvik, C.F., Seals, D.F., Randall, S.K.: The calcium-binding activity of a vacuole-associated, dehydrin-like protein is regulated by phosphorylation. - Plant Physiol. 130: 675-687, 2002.

Jahangir, G.Z., Naz, S., Khan, M.I., Saleem, M.Z.: Rapid RNA extraction from Eucalyptus tree and its down processing for cloning of dehydrin genes. - Adv. Life Sci. 5: 185-191, 2018.

Koag, M.C., Fenton, R.D., Wilens, S., Close, T.J.: The binding of maize DHN1 to lipid vesicles. Gain of structure and lipid specificity. - Plant Physiol. 131: 309-316, 2003.

Koag, M.C., Wilkens, S., Fenton, R.D., Resnik, J., Vo, E., Close, T.J.: The K-segment of maize DHN1 mediates binding to anionic phospholipid vesicles and concomitant structural changes. - Plant Physiol. 150: 1503-1514, 2009.

Laemmli, U.K. Cleavage of structural proteins during the assembly of the head of bacteriophage T4. - Nature 227: 680685,1970

Mouillon, J.M., Gustafsson, P., Harrison, P.: Structural investigation of disordered stress proteins. Comparison of full-length dehydrins with isolated peptides of their conserved segments. - Plant Physiol. 141: 638-650, 2006.

Puhakainen, T., Hess, M.W., Mäkelä, P., Svensson, J., Heino, P., Palva, E.T.: Overexpression of multiple dehydrin genes enhances tolerance to freezing stress in Arabidopsis. - Plant mol. Biol. 54: 743-753, 2004.

Saavedra, L., Svensson, J., Carballo, V., Izmendi, D., Welin, B., Vidal, S.: A dehydrin gene in Physcomitrella patens is required for salt and osmotic stress tolerance. - Plant J. 45: 237-249, 2006.

Xu, W.L., Liu, M.Q., Shen, X., Lu, C.F. Expression of a carrot $36 \mathrm{kD}$ antifreeze protein gene improves cold stress tolerance in transgenic tobacco. - Forest. Studies China 7: 11-15, 2005.

Yakubov, B., Barazani, O., Shachack, A., Rowland, L.J., Shoseyov, O., Goldhirsh, A.G.: Cloning and expression of a dehydrin-like protein from Pistacia vera L. -Trees 19: 224230, 2005.

Yang, Y., He, M., Zhu, Z., Li, S., Xu, Y., Zhang, C., Singer, S., Wang, Y. Identification of the dehydrin gene family from grapevine species and analysis of their responsiveness of various forms of abiotic and biotic stress. - BMC Plant Biol. 54: 743-753, 2012.

Yang, Y., Sun, X., Yang, S., Li, X., Yang, Y.: Molecular cloning and characterization of a novel SK3-type dehydrin gene from Stipa purpurea. - Biochim. biophys. Res. Commun. 448: 145$150,2014$.

Yao, K., Lockhart, K.M., Kalanack, J.J.: Cloning of dehydrin coding sequences from Brassica juncea and Brassica napus and their low temperature-inducible expression in germinating seeds. - Plant Physiol. Biochem. 43: 83-89, 2005.

Zeng, X., Ling, H., Yang, J., Li, Y., Guo, S.: LEA proteins from Gastrodia elata enhance tolerance to low temperature stress in Escherichia coli. - Gene 646: 136-142, 2018. 